\title{
Sporulation in Bacillus subtilis. Establishment of a Time Scale for the Morphological Events
}

\author{
By I. W. DAWES \\ Microbiology Unit, Department of Biochemistry, University of Oxford \\ D. KAY \\ Sir William Dunn School of Pathology, University of Oxford \\ AND J. MANDELSTAM \\ Microbiology Unit, Department of Biochemistry, University of Oxford
}

(Accepted for publication Io January 1969)

SUMMAR Y

\begin{abstract}
Chemostat cultures of Bacillus subtilis can be obtained in which a large proportion of the cells are initiated to sporulation. In a steady-state culture the fraction of cells which exhibit any particular stage of spore development is a function of the time taken for a cell to reach that stage after having been initiated to spore formation, and of the time required for the cell to pass through that stage. Equations describing this relationship have been derived. From these equations and from values for the fractions of cells exhibiting the morphological stages of spore development seen in electron micrographs, a time scale for the morphological events occurring during sporulation has been constructed.

By observing the effect of a sudden decrease in flow rate of a continuous flow system initially at steady state it was possible to time the occurrence of specific events, biochemical or physical, which were connected with the formation of spores. By this means, refractility was shown to be associated with stage $V$.
\end{abstract}

\section{INTRODUCTION}

The sequential nature of the cytological changes which occur during sporulation of bacilli has been demonstrated in Bacillus cereus (Young \& Fitz-James 1959a, $b$; Fitz-James, 1965) and in Bacillus subtilis (Schaeffer, Ionesco, Ryter \& Balassa, I965; Szulmajster, I964; Ryter, I965; Kay \& Warren, I968). In the latter organisms Schaeffer et al. (1965) described eight stages of development (Fig. I). Starting with the vegetative cell (stage $O$ ), in stage I an axial chromatin filament is formed, followed in stage II by the development of a spore septum due to invagination of the cell membrane. During stage III the spore membrane is completed by growth of the spore septum until it encloses the spore chromatin. Stage IV consists of the formation of a cortical layer between the layers of the complete spore membrane; then, in stage V, a spore coat is formed around the cortex. Stage VI is characterized by maturation of the spore inside the mother cell, autolysis of which leads to the free spore, stage VII. Ryter, Ionesco \& Schaeffer (196I) and Ryter (I965) isolated mutants blocked at these various stages of spore development; such cells do not reach the morphological stages which occur after the block. 
Young \& Fitz-James (1959a, b); Schaeffer et al. (1965) and Kay \& Warren (1968) have attempted to time the appearance of these morphological stages and to correlate them with the biochemical processes taking place during sporulation. All these experimenters used cells grown in batch culture and sampled at 30 to $90 \mathrm{~min}$. intervals; for this reason and because cells do not sporulate synchronously the times for the appearance of the stages could not be accurately obtained. The sporulation of $B$. cereus is probably the most synchronous that has been reported, but even then the appearance of refractility was spread over a period of 15 to $30 \mathrm{~min}$. (Young \& Fitz-James, 1959a). In other instances the variability has been greater; for example, in the culture of $B$. subtilis investigated by Kay \&. Warren (1968) the appearance of refractility was spread over about $120 \mathrm{~min}$. for the whole population. Resuspension experiments with B. subtilis give a more defined zero-time but refractility still occurs with a scatter of 90 to I20 min. (Mandelstam \& Waites, I968). It is therefore not surprising that the time scales given by different workers for the morphological events have been inconsistent.

It is shown below that a steady-state continuous culture technique gives more precise values for the time intervals for each of the morphological stages of sporulation to occur. The method depends on the fact that steady-state cultures can be obtained in which a large proportion of the cells are sporulating (Dawes \& Mandelstam, I969). The proportion of such cells exhibiting a particular stage of spore development will increase with the time taken to pass through that stage. By measuring the relative incidence of the stages in a population one can obtain a measure of the duration of each stage. This technique does not depend on synchrony of the sporulation process for accuracy and in principle only one sample is required for examination.

The sequence of morphological events occurring during sporulation can be represented as

$$
X_{0} \rightarrow X_{1} \ldots \rightarrow X_{i} \rightarrow \ldots \rightarrow X_{7},
$$

where $X_{0}$ to $X_{7}$ are the eight stages recognizable by electron microscopy, and $X_{i}$ is any intermediate stage $; x_{0} \ldots x_{7}$ will be used to denote the concentrations of these species. When vegetative cells are initiated to sporulate at a specific rate $k$, then the number of cells which are initiated per unit time is $k x_{0}$. The cells will then pass through the various stages on their way to becoming mature spores $\left(X_{7}\right)$, and will spend a certain amount of time in each. A time scale for the sporulation process can therefore be constructed and $\tau_{i}$ is defined such that stage $X_{i}$ takes time $\tau_{i-1}$ to $\tau_{i}$ from beginning to end. In the hypothetical case in which there is no washout and $k$ and $x_{0}$ are constants

giving

$$
x_{i}=\int_{\tau_{i-1}}^{\tau_{i}} k x_{0} d t
$$

$$
x_{i}=k x_{0}\left(\tau_{i}-\tau_{i-1}\right) \text {. }
$$

The number of cells in any stage is therefore proportional to the time spent in that stage.

In the chemostat, however, the cells exhibiting any particular stage of sporulation become diluted from the culture because of washout. When account is taken of this (Herbert, Elsworth \& Telling, 1956), equation (I) becomes

$$
x_{i}=\int_{\tau_{i-1}}^{\tau_{i}} k x_{0} e^{-D t} d t
$$

where $D$ is the rate of dilution of the culture. 
In a steady state, $x_{0}$ and $k$ are constant, hence

$$
x_{i}=\frac{k x_{0}}{D}\left(e^{-D \tau_{i-1}}-e^{-D \tau_{i}}\right) .
$$

If $e^{-D \tau}$ is plotted against $\tau$, the concentration of cells in stage $X_{i}$ is poportional to the area under the curve between $\tau_{i-1}$ and $\tau_{i}$ (see Fig. I). Moreover, because equation (2) is simply the first approximation of (4), the solution to equation (4) can also be obtained by a method of successive approximation based on the use of equation (2). In this

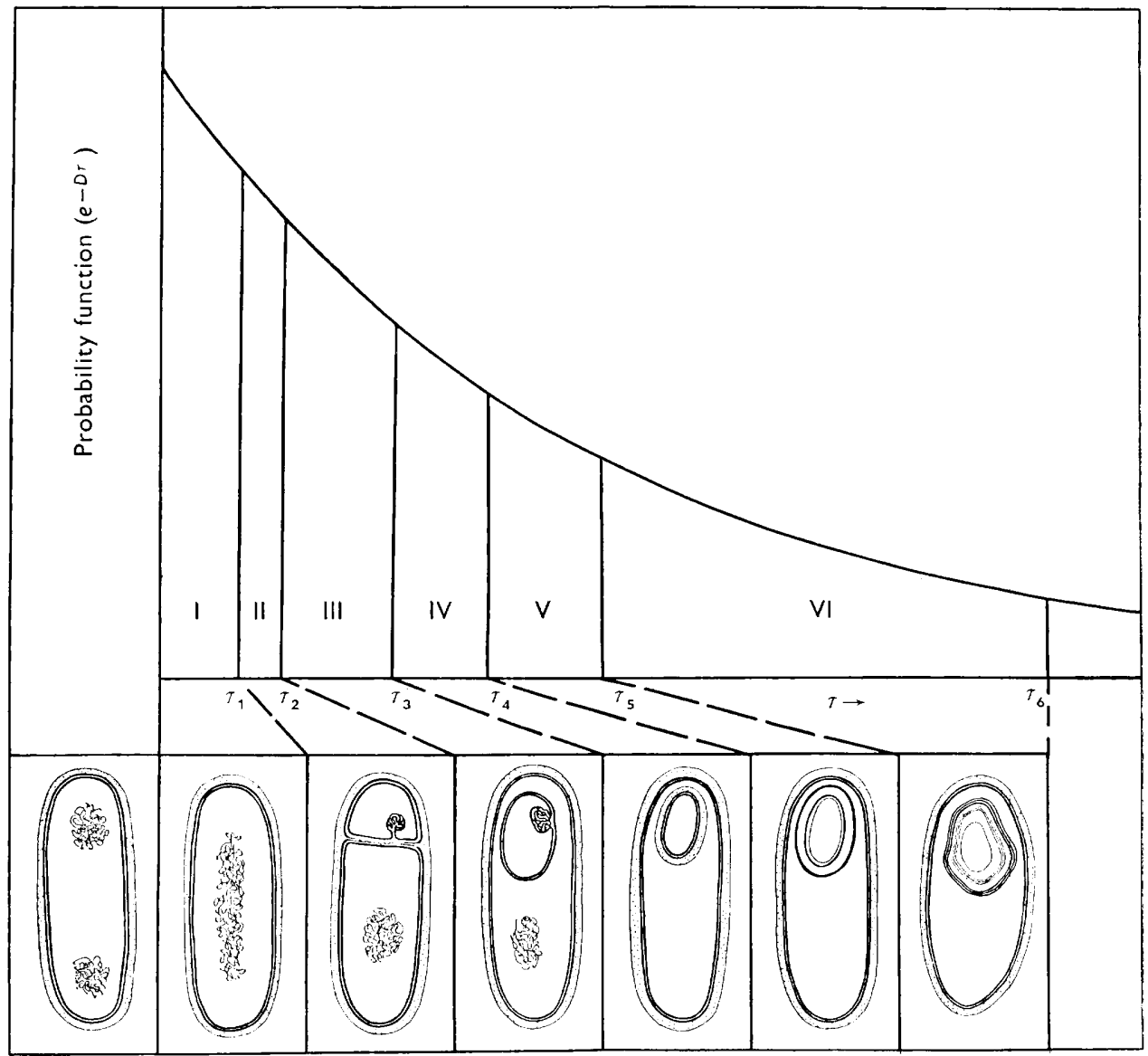

Fig. I. Theoretical curve describing the probability that a cell initiated to sporulation will remain in the chemostat by the time it reaches a particular stage of spore development. The number of cells in each of the stages is proportional to the area in the appropriate segment of the curve (see text). For example, for stage II the number of cells is proportional to the area under the curve between $\tau_{1}$ and $\tau_{2}$. The various stages as defined by Schaeffer $e t$ al. (1965) are indicated.

method values of $\tau_{i}$ calculated by means of (2) are used to 'correct' the observed values of $x_{i}$ for washout. These amended data are then used to recalculate a second set of values of $\tau_{i}$ from (2) and the original values of $x_{i}$ are again amended. This procedure is repeated until the $\tau_{i}$ values no longer undergo significant change.

This method is not readily applicable if stages VI and VII are included, since a 
large number of approximation cycles are required to obtain stable values of $\tau_{i}$. It is less tedious, however, if a reference point can be obtained for the time for the commencement of one of the stages from II to V. This can be done by a second experimental procedure which involves upsetting the steady state of the culture. The probability with which vegetative cells of Bacillus subtilis are initiated to sporulation is a function of the growth rate of the bacteria (Dawes \& Mandelstam, 1969); hence a sudden decrease in the dilution rate of a continuous culture, and hence a decrease in growth rate, leads to a sudden increase in the incidence of refractile spores at an interval after the change. This interval is the time required for a cell to reach refractility after it is initiated to spore formation. Now, it is known that refractility characterizes the later stages of sporulation but the precise correlation with the morphological changes occurring during sporulation is not known. This correlation can be obtained by comparing the results of electron microscopy with those of phase-contrast microscopy. Once a cell has been initiated to spore formation in a chemostat there is a probability that it will be washed out of the vessel before it has reached a particular stage of development; the later the stage, the greater this probability will be. At any steady state the relationship which holds is

$$
y_{i}=\int_{\tau_{i-1}}^{\infty} k x_{0} e^{-D t} d t
$$

where $y_{i}=$ the fraction of cells which are in stage $X_{i}$ and all later stages. Therefore

$$
y_{i}=\left(\frac{k x_{0}}{D}\right) e^{-D \tau_{i-1}}
$$

To correlate refractility with the morphological stages, the fraction of cells which contain refractile spores is determined by direct counting in the phase-contrast microscope; this value is compared with the fractions of cells which have reached each of the morphological stages determined by electron microscopy.

Thus the results in Table $\mathbf{I}$ can be presented as follows:

$\begin{array}{lr}\text { Percentage of cells in stage VII } & 3 \cdot 7 \\ \text { Percentage of cells in stages VI and VII } & 18 \cdot 4 \\ \text { Percentage of cells in stages V to VII (inclusive) } & 23 \cdot 0 \\ \text { Percentage of cells in stages IV to VII (inclusive) } & 27 \cdot 8\end{array}$

From phase-contrast observations the number of cells exhibiting refractility was $22.0 \%$. Thus refractility covers the last three stages and is developed near the beginning of stage $\mathrm{V}$.

One can now determine the times for the beginning of each stage. Equation (5) is a general equation which holds for refractility as well as for any morphological stage. Hence we can write

$$
y_{r}=\left(\frac{k x_{0}}{D}\right) e^{-D t_{r}}
$$

where $y_{r}$ is the fraction of cells showing refractility, and $t_{r}$ is the time required for a cell to reach refractility. From equations (5) and (6) one can show that $\tau_{i-1}$, the time for the beginning of stage $X_{i}$ is given by

$$
\tau_{i-1}=t_{r}-\frac{1}{D} \ln \left(\frac{y_{i}}{y_{r}}\right) \text {. }
$$

It is not necessary to use the method of successive approximation if the above procedure is adopted, since from equation (7) the time at which any intermediate 
stage begins $\left(\tau_{i-1}\right)$ can be determined. The approximation procedure has been presented, however, since it is a method for solving equation (4) in the case of mutants not forming refractile spores.

\section{METHODS}

Organism. Bacillus subtilis (Marburg strain 168), auxotrophic for indole or tryptophan, was stored as a spore suspension.

Cultivation. Continuous cultivation was carried out at $37^{\circ}$ in a chemostat containing $100 \mathrm{ml}$. of culture stirred by vigorous aeration (I $1 . \mathrm{min}^{-1}$ of sterile-filtered humidified air). Medium was fed into the vessel by means of a peristaltic pump and the culture maintained at constant volume with a syphon.

The medium used was a modification of that used by Donnellan, Nags \& Levinson (1964), with no ammonium ion present and with glutamate at a limiting concentration of $\mathrm{I} \cdot 36 \mathrm{~mm}$. Growth under these conditions was limited by nitrogen. The concentration of $\mathrm{Mg}^{2+}$ was $25 \mathrm{~mm}$; this gave a higher yield of spores.

The spore inoculum, suspended in $\mathrm{I} 0 \mathrm{ml}$. of $\mathrm{I} \%$ hydrolysed casein medium (Mandelstam \& Waites, 1968), was added to the culture vessel, which was heated to $80^{\circ}$ to decrease contamination by vegetative bacteria that might have been introduced during inoculation. After Io min. at $80^{\circ}$ the vessel was cooled to $37^{\circ}$ and aeration and medium flow started. When growth became limited, about $90 \%$ of the culture was run out of the vessel and fresh medium added to dilute out residual amino acids. The chemostat was allowed to reach a steady state at a dilution rate of $0.134 \mathrm{hr}^{-1}$.

Electron microscopy. A sample $(5 \mathrm{ml}$.) was taken from the chemostat, treated with fixative $(0.5 \mathrm{ml}$.), centrifuged and the pellet fixed without resuspension by the method of Kellenberger, Ryter \& Séchaud (1958). After staining in uranyl acetate $(0.5 \%$ in Kellenberger buffer), the cells were dehydrated in graded ethanol and embedded in Araldite. Sections were cut from the Araldite blocks and stained with lead citrate (Reynolds, 1963).

Counting procedures. Counts of the cells exhibiting the eight stages of sporulation were obtained by examination of 43 electron micrographs with a hand lens. Only complete longitudinal sections were scored, since in a transverse section a developing spore might be missed altogether, and the stage of development would have been more difficult to recognize. From the 43 plates, 434 longitudinal cell-sections were counted.

The fraction of the cells in the culture containing refractile spores was estimated by direct counting of a cell sample, fixed in formaldehyde, under the phase-contrast microscope. For study of the effect of dilution rate changes on spore incidence at least IOO spores were counted; for the steady state sample 400 spores were counted. For any particular flow rate the incidence of spores in different cultures was reproducible to within about $\mathrm{I} \%$.

\section{RESULTS}

Stages of sporulation in a steady state continuous culture

For the chemostat operating at a dilution rate of $0 \cdot 134 \mathrm{hr}^{-1}$ (compared with the maximum specific growth rate of $0.467 \mathrm{hr}^{-1}$ obtainable in our conditions) the fraction of the total cell population containing refractile spores was $0 \cdot 220$, obtained by direct counting. The number of cells in the various morphological stages of sporulation obtained from examination of the electron micrographs are given in Table $\mathrm{I}$, together 
with the fraction of the total cell population present in each stage. It was easy to recognize the stages of development in the electron micrographs except for stages $\mathrm{V}$ and VI. Distinguishing these stages requires a decision as to whether the spore coat structures are complete, or are still being synthesized: hence the time for completion of stage $\mathrm{V}$ given below is approximate.

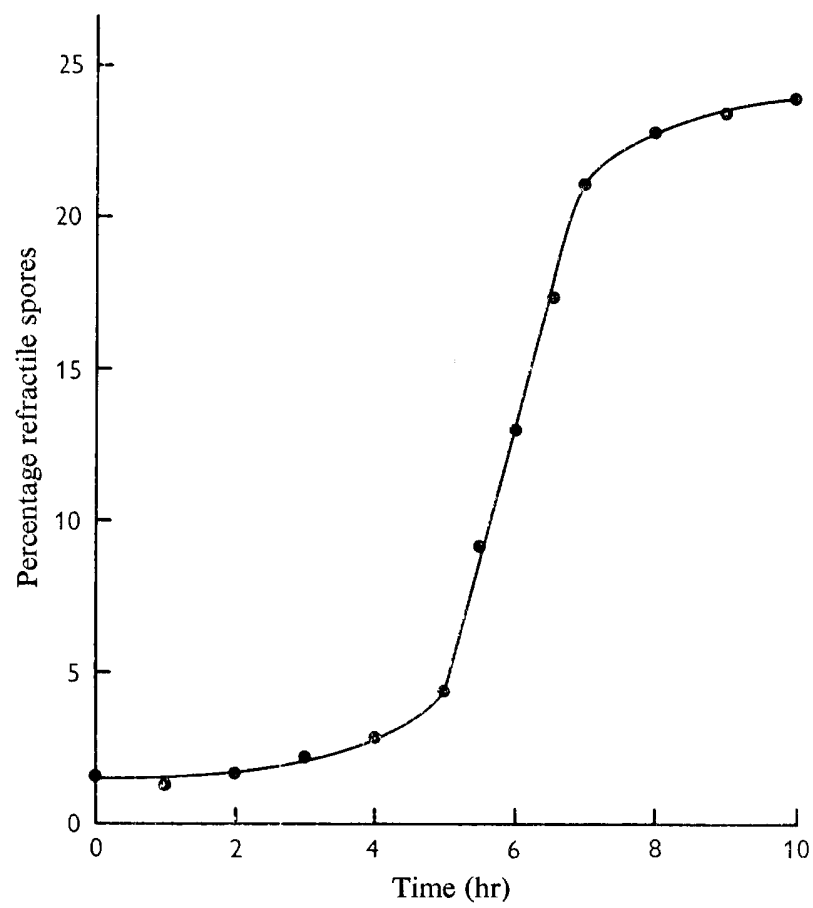

Fig. 2. Bacillus subtilis $\mathbf{1} 68$. The time taken for the appearance of refractile spores after initiation of cells to spore formation. At zero time the dilution rate of a steady state culture was changed from $0.42 \mathrm{hr}^{-1}$ to $0.13 \mathrm{hr}^{-1}$. After $6 \mathrm{hr}$ a sudden increase in spore incidence occurs.

Table I. Bacillus subtilis r68. Counts of cells in the various morphological stages of sporulation

A sample was taken from a steady state continuous culture system operating at a dilution rate of $0 \cdot 134 \mathrm{hr}^{-1}$. The cells were sectioned and examined by electron microscopy, and those giving complete longitudinal sections were scored for the various stages as defined by Schaeffer et al. (1965).

Stage
O
I
II
III
IV
V
VI
VII

Number of cells in stage

235
32
18
28
21
20
64
16

Fraction of cells in stage

$$
\begin{aligned}
& 0.542 \\
& 0.074 \\
& 0.042 \\
& 0.065 \\
& 0.048 \\
& 0.046 \\
& 0.147 \\
& 0.037
\end{aligned}
$$




\section{The time taken for an initiated cell to produce a refractile spore}

The time taken for the appearance of refractility was determined as described in the introduction by observing the effect on the incidence of refractile spores of a sudden decrease in the flow rate of the medium. Figure 2 shows the incidence of refractile spores in the culture after a sudden decrease in the dilution rate from a steady state value of $0.42 \mathrm{hr}^{-1}$ to one of $0.13 \mathrm{hr}^{-1}$. An increase occurred at an average of $6.0 \mathrm{hr}$ after the decrease in flow rate. This has been taken as the time required for the development of a refractile spore from a vegetative cell.

\section{Times for the completion of the morphological stages of sporulation}

Table I shows that stages V, VI and VII together comprised $23.0 \%$ of the total culture population. The percentage of refractile spores in the culture was $22.0 \%$. It therefore appeared that refractility occurred just after the beginning of stage $\mathrm{V}$, since if it began at stage VI, for example, stages VI and VII together would have been more than $22 \%$ of the culture population. From these two percentages and the time of $6 \cdot 0 \mathrm{hr}$ for the appearance of refractility, the washout equation (7) was used to calculate that the average time taken for the cells to reach stage $\mathrm{V}$ was $5.7 \mathrm{hr}$ after initiation. This time and the method of successive approximation was then used to calculate the times taken for each of the other stages (Table 2). The results were checked by substitution in equation (4), and the ratios of observed cell counts in the different stages to those calculated by means of equation (4) have been included in Table 2.

\section{Table 2. Bacillus subtilis I68. Times taken for completion of the morphological stages of sporulation}

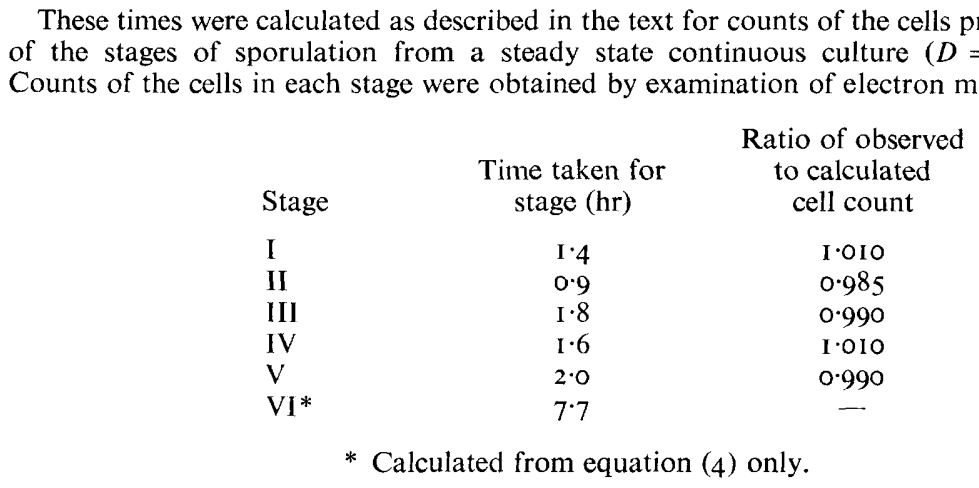

\section{DISCUSSION}

These experiments were done to establish the value of the continuous culture technique in determining the time scale for the morphological changes which take place during sporulation. The procedure described has several advantages over methods using batch cultures for the same purpose. For accuracy, a batch culture experiment depends upon the use of a synchronized culture and the treatment for electron microscopy of a large number of samples taken during the whole period of sporulation. It is difficult to achieve synchrony in cultures of Bacillus subtilis I 68 for 
several reasons. The organisms tend to grow as filaments which often contain as many as 6 cells and occasionally more. This means that young cells cannot be separated from old cells, so that it is not easy to apply the membrane-filter technique of Anderson \& Pettijohn (1960). Other procedures for obtaining synchrony, such as starving the organisms of an amino acid, are themselves likely to initiate some of the changes connected with sporulation. By contrast, the continuous culture method avoids the need for synchrony and in principle requires only one sample for examination. In addition, it is intrinsically more exact, since any specified degree of accuracy can be obtained by scoring a sufficient number of sections.

A possible source of error in the continuous culture method arises from spore germination and, in fact, a low percentage of germinating spores was observed in the electron micrographs. A correction for germination can be made by modification of the equations characterizing sporulation in continuous culture, but this was not considered necessary here because of the low percentage of germinating spores.

A check on the accuracy of the data obtained from scoring of the electron micrographs was made by comparing the results of electron microscopy with those of phase-contrast microscopy. The latter suggested that the fraction of cells containing refractile spores was 0.22 and that the time required to reach refractility was $6.0 \mathrm{hr}$. From these data and equation (5) it can be calculated that the fraction of cells in one or other stage of sporulation should be 0.45 . The value from the electron micrographs was 0.46 . Moreover, the agreement of these values provides another indication that spore germination is not a significant source of error in this system.

Additional information about the sporulation process can be obtained from continuous cultures by the use of sudden changes in the dilution rate of a culture at steady state. A sudden decrease in the flow rate provides a convenient and general method for investigating the time of appearance of any event connected with sporulation. Its present application to the development of refractility shows that under our conditions this occurred at the beginning of stage $\mathrm{V}$. This agrees with the findings of Warren (1968), who used a batch culture technique with the same strain of Bacillus subtilis that we have used, and those of Fitz-James (I965), who worked with B. cereus. It contradicts the suggestion (Murrell, 1967) that refractility is associated with stage III. A further extension of this technique could be in the investigation of the successive biochemical events of sporulation. These include, for example, increases in alkaline phosphatase, glucose dehydrogenase and dipicolinic acid (see Schaeffer et al. 1965; Szulmajster, 1964; Warren, I968; Mandelstam, 1969).

The authors thank Dr J. H. M. Thornley and Dr W. M. Waites for their criticism and advice. We are indebted to Mrs Wendy Brownsill for skilled technical assistance.

This work was supported by a grant from the Science Research Council. I. W. D. is a Rhodes Scholar.

\section{REFERENCES}

Anderson, P. A. \& Petrujohn, D. E. (1960). Synchronization of division in Escherichia coli. Science, N.Y. I3I, 1098.

Dawes, I. W. \& Mandelstam, J. (I969). Biochemistry of sporulation of Bacillus subtilis I68: continuous culture studies. Proc. 4th int. Symp. Continuous Cultivation of Micro-organisms, Prague (in the Press). 
Donnellan, J. E., Nags, E. H. \& Levinson, H. H. (1964). Chemically-defined synthetic media for sporulation and germination of Bacillus subtilis. J. Bact. 87, 332.

FITZ-JAMES, P. C. (I965). Spore formation in wild and mutant strains of Bacillus cereus and some effects of inhibitors. Colloques int. Cent. natn. Rech. scient., Marseille, p. 529.

Herbert, D., Elsworth, R. \& Telling, R. C. (1956). The continuous culture of bacteria; a theoretical and experimental study. J. gen. Microbiol. 14, 601.

KAY, D. \& WARREN, S. C. (I968). Sporulation in Bacillus subtilis. Morphological changes. Biochem. J. I09, 8 I9.

Kellenberger, E., Ryter, A. \& Séchaud, J. (I958). Electron microscope study of DNA-containing plasma, II: vegetative and mature phage DNA as compared with normal bacterial nucleoids in different physiological stages. J. biophys. biochem. Cytol. 4, 67 I.

Mandelstam, J. (1969). Regulation of bacterial spore formation. Symp. Soc. gen. Microbiol. x9, 377.

Mandelstam, J. \& Waites, W. M. (1968). Sporulation in Bacillus subtilis. The role of exoprotease. Biochem. J. Io9, 793.

Murrell, W. G. (1967). Biochemistry of the bacterial endospore. Adv. Microbiol. Physiol. I, I33.

REYNOLDS, E. S. (1963). The use of lead citrate at high pH as an electron-opaque stain in electron microscopy. J. Cell Biol. r7, 208.

Ryter, A. (I965). Étude morphologique de la sporulation de Bacillus subtilis. Annls Inst. Pasteur, Paris, ro8, 40 .

RYTER, A., IONESCO, H. \& SCHAFFER, P. (I961). Étude au microscope électronique de mutants asporogènes de Bacillus subtilis. C. r. hebd. Séanc. Acad. Sci., Paris, 252, 3675.

Schaeffer, P., Ionesco, H., Ryter, A. \& Balassa, G. (1965). La sporulation de Bacillus subtilis; étude génétique et physiologique. Colloques int. Cent. natn. Rech. scient., Marseille, p. 553.

Szulmajster, J. (1964). Biochemie de la sporogénèse chez Bacillus subtilis. Bull. Soc. Chim. biol. 46, 443.

WARREN, S. C. (1968). Sporulation in Bacillus subtilis. Biochemical changes. Biochem. J. 109, 8I I.

YounG, I. E. \& Fitz-JAMES, P. C. (I959a). Chemical and morphological studies of bacterial spore formation, I: the formation of spores in Bacillus cereus. J. biophys. biochem. Cytol. 6, 467.

Young, I. E. \& Fitz-JAMES, P. C. (1959b). Chemical and morphological studies of bacterial spore formation, II: spore and parasporal protein formation in Bacillus cereus var. Alesti. J. biophys. biochem. Cytol. 6, 483 . 
